\title{
Pemetaan Kinerja Ruas Jalan Provinsi Kabupaten Kediri di Provinsi Jawa Timur Dengan Menggunakan Metode SIG
}

\author{
Kurnia Hadi Putra ${ }^{1}$, Jesika Mareta ${ }^{2}$ \\ ${ }^{1,2}$ Program Studi Teknik Sipil, Fakultas Teknik Sipil dan Perencanaan, Instritit Teknologi Adhi Tama Surabaya \\ Email: ${ }^{1}$ kurnia_putra@itats.ac.id
}

\begin{abstract}
Data gained from Central Bureau of Statistics in Kediri Regency in 2017 reported that the number of people within the last four years has increased to 4.22\%. Based on the data of Public Works Office, the similar improvement also occurred on the traffic value of Ahmad Yani road in Kediri Regency in 2017 by > 60,000 vehicles/day. This condition has brought effects to road users and Level of Service of road. Therefore, area mapping of provincial road performance is required. The mapping is also applied to some roads influencing the development system of Kediri Regency Government using Geographic Information System or Sistem Informasi Geografi (SIG) method. It can assist Public Works Office, Bina Marga, East Java in finding solution to overcome problems of traffic routes. Data on traffic volume and road capacity were then analyzed based on MKJI 1997 to get saturation degree and road service level. The analysis on saturation degree on provincial roads in Kediri Regency obtained ratios of $00.00-0.20,0.20-0.44$, and $0.45-0.74$. Ahmad Yani road had saturation degree ratio by 0.85-1.00 and > 1.00. Level of Service (LoS) on the provincial roads of Kediri Regency was light green, green, and yellow in the categories of $A$, $B$, and C. However, Ahmad Yani road got purple and red with Level of Service (LoS) in categories $E$ and $F$.
\end{abstract}

Keywords: road capacity, road performance, road service level, saturation degree, Sistem Informasi Geografis (SIG)

\begin{abstract}
Abstrak
Data Badan Pusat Statistik Kabupaten Kediri tahun 2017 terjadi peningkatan jumlah penduduk di Kabupaten Kediri 4 tahun terakhir dengan presentase 4,22\% dan data volume lalu lintas jalan provinsi di Kabupaten Kediri tahun 2017 dari Dinas Pekerjaan Umum Jawa Timur terjadi peningkatan volume lalu lintas pada jalan A. Yani > 60.000 kendaraan/hari. Kondisi ini berdampak pada peningkatan pengguna jalan dan tingkat pelayanan jalan (Level of Service) suatu ruas jalan. Sehingga diperlukaannya pemetan wilayah kinerja ruas jalan provinsi dengan jalan mana saja berdampak pada sistem pembangunan pemerintahan Kabupaten Kediri dengan berbasis SIG yang dapat membantu Dinas Pekerjaan Umum Bina Marga Jawa Timur dalam menemukan solusi untuk mengatasi masalah yang terjadi pada arus jalan lalu lintas, berdasarkan data volume lalu lintas, dan kapasitas jalan yang di analisa berdasarkan MKJI 1997 untuk mendapatkan nilai derajat kejenuhan, dan tingkat pelayanan jalan. Analisis Derajat kejenuhan jalan provinsi di Kabupaten Kediri menunjukkan sebagian besar memiliki nilai rasio sebesar $00.00-0.20,0.20$ 0.44 , dan 0.45 - 0.74. Pada ruas jalan A. Yani menunjukan rasio derajat kejenuhan sebesar 0.851.00 dan $>1.00$. Tingkat pelayanan jalan $(\mathrm{LoS})$ pada ruas jalan provinsi di Kabupaten Kediri sebagian besar berwarna hijau muda, hijau, dan kuning dengan kategori A, kategori B dan kategori C. Namun tidak pada ruas jalan A. Yani yang terlihat berwarna ungu dan merah memiliki tingkat pelayanan jalan (LoS) dengan kategori E dan kategori F.
\end{abstract}

Keywords: Derajat kejenuhan, Kapasitas jalan, Kinerja jalan, Sistem Informasi Geografis (SIG), Tingkat pelayanan jalan. 


\section{Latar Belakang}

Kota Kediri merupakan kota dengan populasi terbanyak nomer 3 di Provinsi Jawa Timur, luas area 138.605 Ha terbagi 26 Kecamatan, 343 Desa 1 Kelurahan. Data Badan Pusat Statistik Kabupaten Kediri tahun 2017 terjadi peningkatan jumlah penduduk 4 tahun terakhir dengan presentase 4,22\% dan data volume lalu lintas jalan provinsi di Kabupaten Kediri tahun 2017 dari Dinas Pekerjaan Umum Jawa Timur terjadi peningkatan volume lalu lintas pada jalan A. Yani $>60.000$ kendaraan/hari. Kondisi ini mempengaruhi jalan-jalan provinsi yaitu bagian barat jalan provinsi Kediri menghubungkan Tulungagung dan Nganjuk, disisi utara jalan provinsi di Kabupaten Kediri menghubungkan Nganjuk Jombang, dibagian timur jalan provinsi di Kediri menghubungkan Jombang dan Malang dan dibagian selatan jalan provinsi di Kediri menghubungkan Blitar dan Tulungagung.

Hal ini pasti membawa dapak yang signifikan terhadap kemacetan di ruas jalan tersebut. Sehingga diperlukan pemetaan wilayah kinerja ruas jalan provinsi untuk mengetahui ruas wilayah jalan mana saja, yang berdampak pada sistem pembangunan pemerintahan Kabupaten Kediri. Berdasarkan permasalahan tersebut, maka dilakukan penelitan menganalisis kinerja ruas jalan provinsi di Kabupaten Kediri dengan menggunakan metode MKJI 1997 dan pemetaan menggunaan SIG. Diharapkan dengan adanya penelitian kinerja ruas jalan provinsi di Kabupaten Kediri dapat membantu memberikan informasi yang jelas akan terkait titik ruas jalan yang mengalami kemacetan.

\section{Metode Penelitian}

\subsection{Lokasi Penelitian}

Lokasi penelitian dilakukan dibeberapa ruas jalan provinsi di Kabupaten Kediri meliputi, ruas Jalan Cokroaminoto, Jalan Veteran, Jalan Gajah Mada, Jalan Letjen Sutoyo, Jalan Pahlawan, Jalan Sersan Bahrun, Jalan Gatot Subroto, Jalan Ahmad Dahlan, Jalan Kapten Tendean, Jalan A. Yani, Jalan Ki Hajer Dewantoro, Jalan Dr. Wahidin S, Jalan Panglima Polim, Jalan Mayor Bismo, Jalan WR Supratman, Jalan P. Sudirman, Jalan Dr. Soetomo, Jalan Soekarno - Hatta. Dapat dilihat pada Gambar 1 terkait lokasi dalam penelitian ini

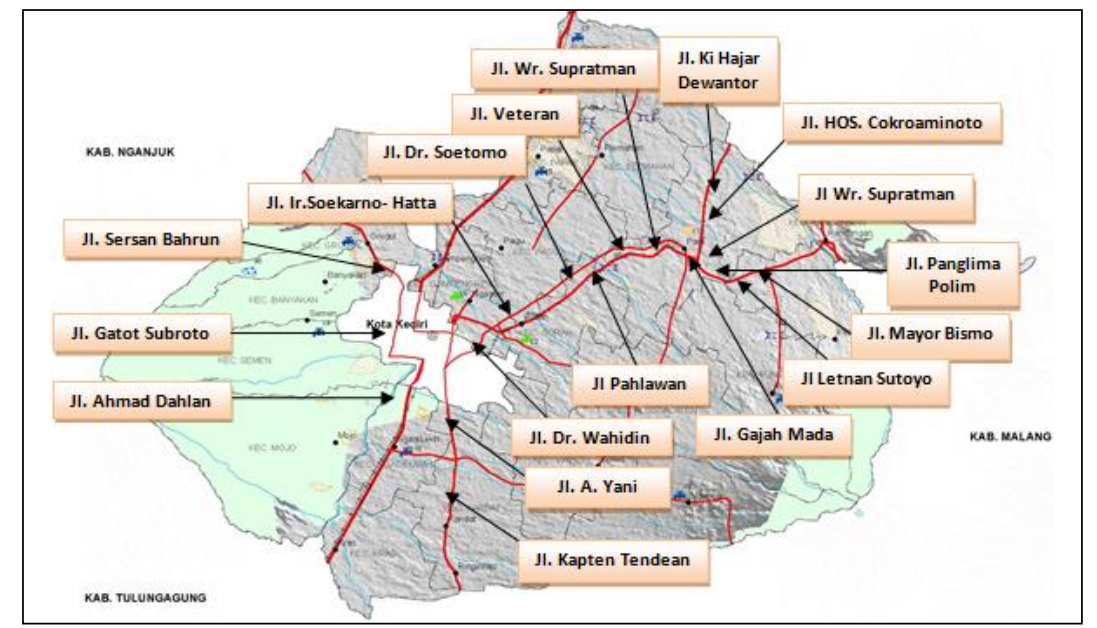

Gambar 1. Lokasi Survei Kinerja Ruas Jalan Provinsi Kabupaten Kediri

\subsection{Prosedur Penelitian}

Tahapan penelitian ini bertujuan untuk menentukan tahapan - tahapan yang akan dilakukan guna memenuhi yang akan dicapai dalam penelitian ini. Adapun tahapan dapat dilihat detail sebagai berikut : 


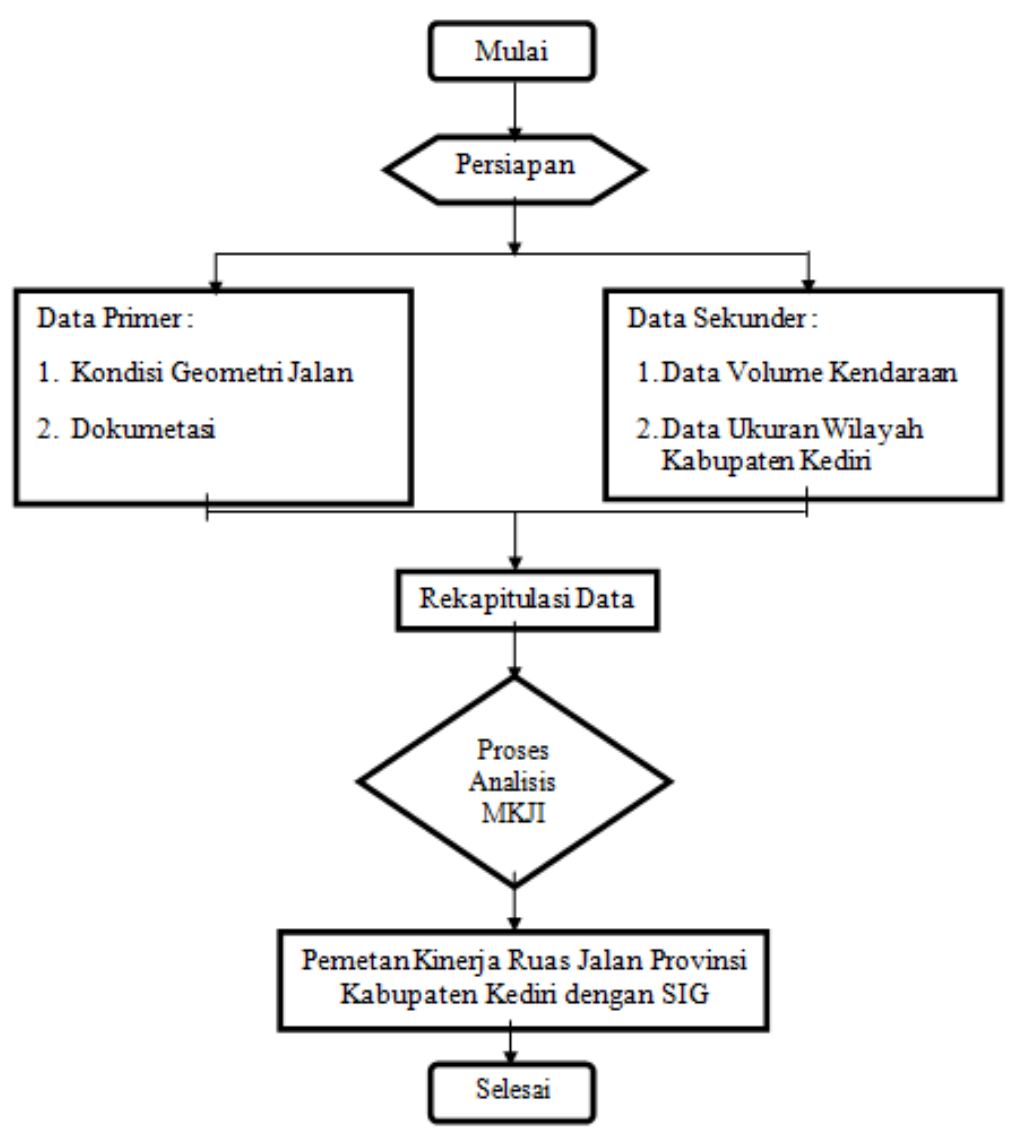

Gambar 2. Bagan Alir Prosedur Penelitian

\subsection{Teknik Pengumpulan Data}

Pengambilan data - data ini dapat dibedakan atas data primer dan data sekunder.

\subsubsection{Data Primer}

Data Primer adalah data yang diambil langsung dari survei. Data - data primer ini meliputi: (1) Geometri jalan meliputi lebar jalur; kecepatan arus bebas dan kapasitas meningkat dengan pertambahan lebar jalur lalu-lintas, bahu/kereb, hambatan jalan; (2) Dokumentasi berupa gambar gambar survei lapangan Pemetaan Kinerja Ruas Jalan Provinsi Kabupaten Kediri.

\subsubsection{Data Sekunder}

Data sekunder adalah data yang didapat dari berbagai sumber yang telah ada atau dari instansi-instansi terkait sesuai dengan objek penelitian. Data - data sekunder ini meliputi: (1) Data Volume Kendaraan yaitu kapasitas atau jumlah kendaraan dalam ruas jalan yang didapat dari Dinas Pekerjaan Umum Jawa Timur; (2) Data Ukuran Wilayah Kabupaten Kediri. Data berupa data jumlah penduduk Kabupaten Kediri yang didapat dari Biro Pusat Statistik Kabupaten Kediri.

\subsection{Teknik Analisi Data}

Setelah selesainya survei lokasi penelitian, data - data yang ada dikumpulkan, tahap selanjutnya yang dilakukan adalah memproses atau mengelola data berdasarkan bagan alir yang terdapat dalam Manual Kapasitas Jalan Indonesia 1997 untuk Kinerja Ruas Jalan Provinsi dan Pemetaan menggunakan program SIG. Data - data tersebut meliputi : (1) Volume Lalu Lintas adalah 
bebas suatu dalam dalam bentuk kendaraan yang melintasi jalan; (2) Derajat Kejenuhan atau Degree of Saturation (DS) adalah Rasio dari arus lalu-lintas terhadap kapasitas untuk suatu pendekat. dengan perbandingan $\mathrm{Q}$ adalah arus kendaraan yang melewati ruas jalan (smp/jam) dan $\mathrm{C}$ adalah nilai kapasitas jalan tersebut (smp/jam); (3) Tingkat pelayanan jalan (level of service) adalah suatu ukuran yang digunakan untuk mengetahui kualitas suatu ruas jalan tertentu illustrasi melayani arus lalu lintas yang melewatinya. Tingkat pelayanan merupakan suatu konsep yang mengikut sertakan dua buah faktor yang saling bertentangan yakni kecepatan rata-rata ruang volume lalu lintas (MKJI, 1997); (4) Dalam pemetan kinerja ruas jalan provinsi Kabupaten Kediri ini menggunakan program SIG (Sistem Informasi Geografis). Data - data yang digunakan yaitu data volume kendaraan Kabupaten Kediri yang didapat dari Dinas PU Kabupaten Kediri, data ukuran wilayah Kabupaten Kediri yang didapat dari Biro Pusat Statistik Kabupaten Kediri, data Spasial Pencitraan satelit Open Street Map (OSM) wilayah Kabupaten Kediri yang didapat dari aplikasi SIG. Tahapan analisis data yang dilakukan adalah : (1) Data dikelola dari hasil tinjauan lokasi dan pengumpulan data yang terkait dengan karakteristik lalu lintas jalan Kabupaten Kediri dalam program microsof excel; (2) Data yang sudah dikelola pada microsoft excel dilanjutkan pada program SIG dengan cara membuat formulasi data sebagai bahan analisa untuk mengetahui tingkat presentase karakteristik jaringan jalan secara spasial; (3) Data hasil analisis tersebut dipetakan dan diplotkan pada gambar geografis jalan provinsi Kabupaten Kediri menurut kategori pewarnaan jalan sesuai dengan asumsi penulis; Data pemetaan tersebut dicetak sesuai kebutuhan penulis.

$$
D S=\frac{Q}{C}
$$

\section{Hasil dan Pembahasan}

\subsection{Pemetaan Berdasarkan Volume Lalu Lintas Jalan Provinsi di Kabupaten Kediri}

Volume lalu lintas dikategorikan dan dipetakan berdasarkan jenis kendaraan yang dihitung berdasarkan jumlah kendaraan perjam, dan satuan mobil penumpang (SMP) perjam. Berikut lebih jelasnya dapat dilihat pada Tabel 1 Volume Lalu Lintas Jalan Provinsi di Kabupaten Kediri.

Berdasarkan nilai volume lalu lintas berdasar warna pada ruas jalan sesuai dengan asumsi penulis, seperti garis ruas jalan berwarna hijau muda memiliki nilai $100-500 \mathrm{smp} / \mathrm{jam}$, warna hijau dengan nilai $500-1.000 \mathrm{smp} / \mathrm{jam}$, warna kuning dengan nilai $1.000-1.500 \mathrm{smp} / \mathrm{jam}$, warna orange dengan nilai $1.500-2.000 \mathrm{smp} / \mathrm{jam}$, warna merah muda dengan nilai $2.000-2.500 \mathrm{smp} / \mathrm{jam}$, warna merah dengan nilai $2.500-3.000 \mathrm{smp} / \mathrm{jam}$, dan warna ungu dengan nilai $>3.000 \mathrm{smp} / \mathrm{jam}$. Seperti pada Gambar 4,5,6, dan 7 pemetaan volume lalu lintas jalan provinsi di Kabupaten Kediri berdasarkan volumenya (SMP/jam) dibawah ini. 
Tabel 1. Volume lalu lintas jalan provinsi di Kabupaten Kediri

\begin{tabular}{|c|c|c|c|c|c|c|c|c|c|}
\hline \multirow[t]{2}{*}{ No. } & \multirow[t]{2}{*}{ Nama Ruas } & \multirow[t]{2}{*}{$\begin{array}{c}\text { Jam Puncak } \\
\text { Arah } 1 \\
\text { (kend/jam) }\end{array}$} & \multicolumn{3}{|c|}{$\begin{array}{c}\text { Jumlah } \\
\text { Kendaraan Arah } 1 \\
\text { (Kend/Jam saat } \\
\text { Jam Puncak) }\end{array}$} & \multirow[t]{2}{*}{$\begin{array}{c}\text { Jam } \\
\text { Puncak } \\
\text { Arah } 2 \\
\text { (kend/jam) }\end{array}$} & \multicolumn{3}{|c|}{$\begin{array}{c}\text { Jumlah Kendaraan } \\
\text { Arah } 2 \text { (Kend/Jam } \\
\text { saat Jam Puncak) }\end{array}$} \\
\hline & & & $\mathbf{L V}$ & HV & MC & & $\mathbf{L V}$ & HV & MC \\
\hline \multicolumn{10}{|c|}{ Wilayah. Kabupaten Kediri } \\
\hline 1 & JL. HOS Cokroaminoto & 1026 & 184 & 86 & 756 & 878 & 187 & 39 & 652 \\
\hline 2 & JL. Ki Hajar Dewantara & 483 & 68 & 49 & 366 & 466 & 37 & 5 & 424 \\
\hline 3 & JL. Veteran & 624 & 26 & 4 & 594 & 399 & 73 & 50 & 276 \\
\hline 4 & JL. Wahidin Sudiro & 776 & 123 & 17 & 636 & 860 & 93 & 53 & 714 \\
\hline 5 & JL. Gajah Mada & 1109 & 80 & 35 & 994 & 1097 & 29 & 5 & 1063 \\
\hline 6 & Jl. Panglima Polim & 1112 & 21 & 4 & 1087 & 327 & 65 & 36 & 226 \\
\hline 7 & JL. Mayor Bismo & 1082 & 257 & 73 & 752 & 1127 & 140 & 48 & 939 \\
\hline 8 & JL. Letjen Sutoyo & 1637 & 66 & 1 & 1570 & 1615 & 221 & 68 & 1326 \\
\hline 9 & JL. WR. Supratman & 2438 & 194 & 11 & 2233 & 0 & 0 & 0 & 0 \\
\hline 10 & JL. P. Sudirman & 1488 & 188 & 5 & 1295 & 1439 & 318 & 5 & 1116 \\
\hline 11 & JL. Pahlawan & 2394 & 156 & 4 & 2234 & 2637 & 374 & 1 & 2262 \\
\hline 12 & JL. Dr. Soetomo & 1454 & 265 & 89 & 1100 & 1803 & 169 & 12 & 1622 \\
\hline 13 & JL. Soekarno - Hatta & 3096 & 200 & 24 & 2872 & 1903 & 244 & 35 & 1624 \\
\hline \multicolumn{10}{|c|}{ Wilayah. Kota Kediri } \\
\hline 14 & JL. Sersan Bahrun & 2493 & 205 & 81 & 2207 & 1545 & 211 & 111 & 1223 \\
\hline 15 & JL.Gatot Subroto & 3696 & 426 & 74 & 3196 & 5287 & 216 & 90 & 4981 \\
\hline 16 & JL. Ahmad Dahlan & 3827 & 439 & 127 & 3261 & 5287 & 216 & 90 & 4981 \\
\hline 17 & JL. Kapten Tendean & 2834 & 323 & 63 & 2448 & 2174 & 481 & 90 & 1603 \\
\hline 18 & JL. A. Yani & 4111 & 242 & 27 & 3842 & 3658 & 162 & 1 & 3495 \\
\hline
\end{tabular}

Sumber: Dinas PU Bina Marga Provinsi Jawa Timur

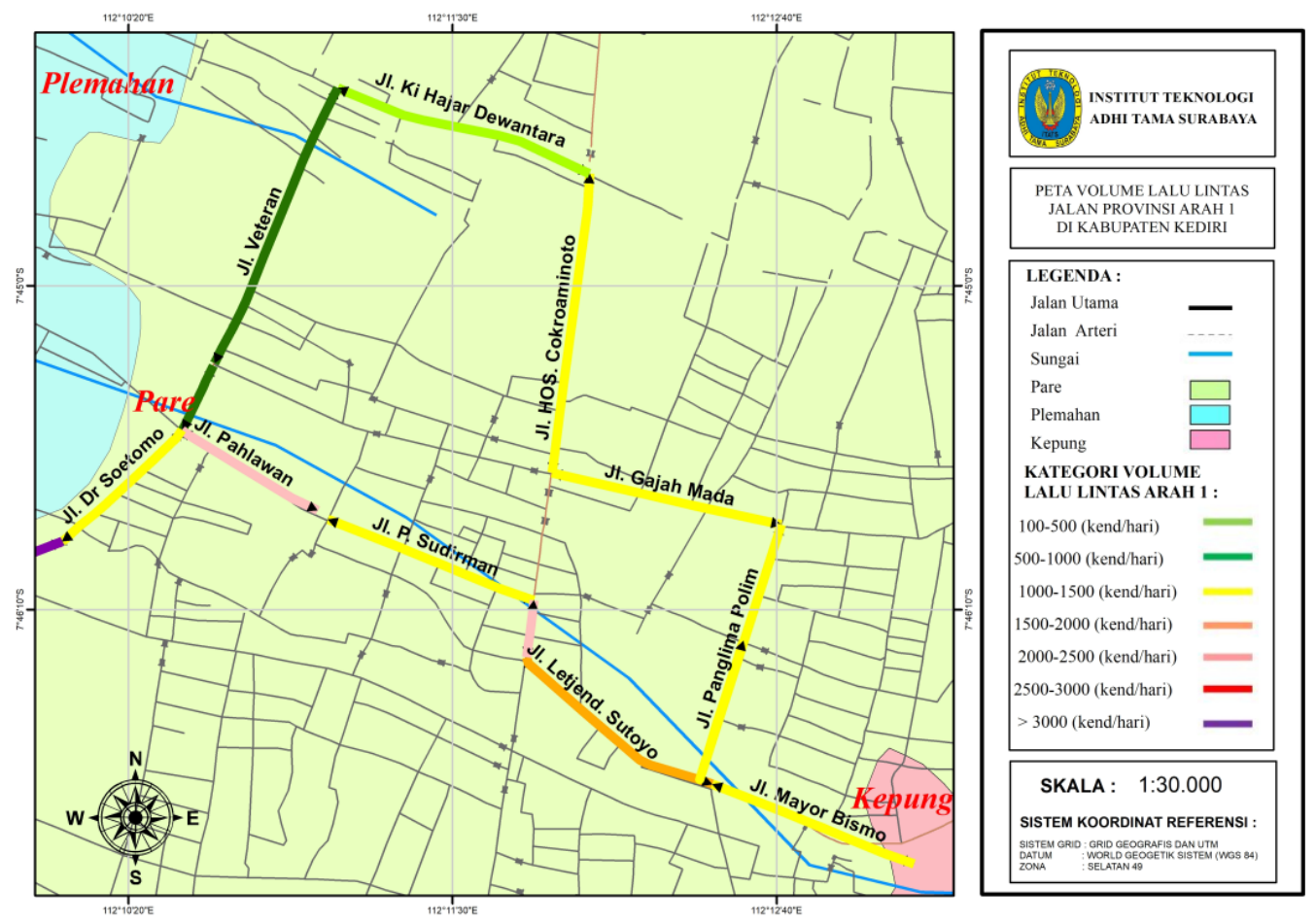

Gambar 3. Pemetaan volume lalu lintas jalan provinsi arah 1 di Kabupaten Kediri 


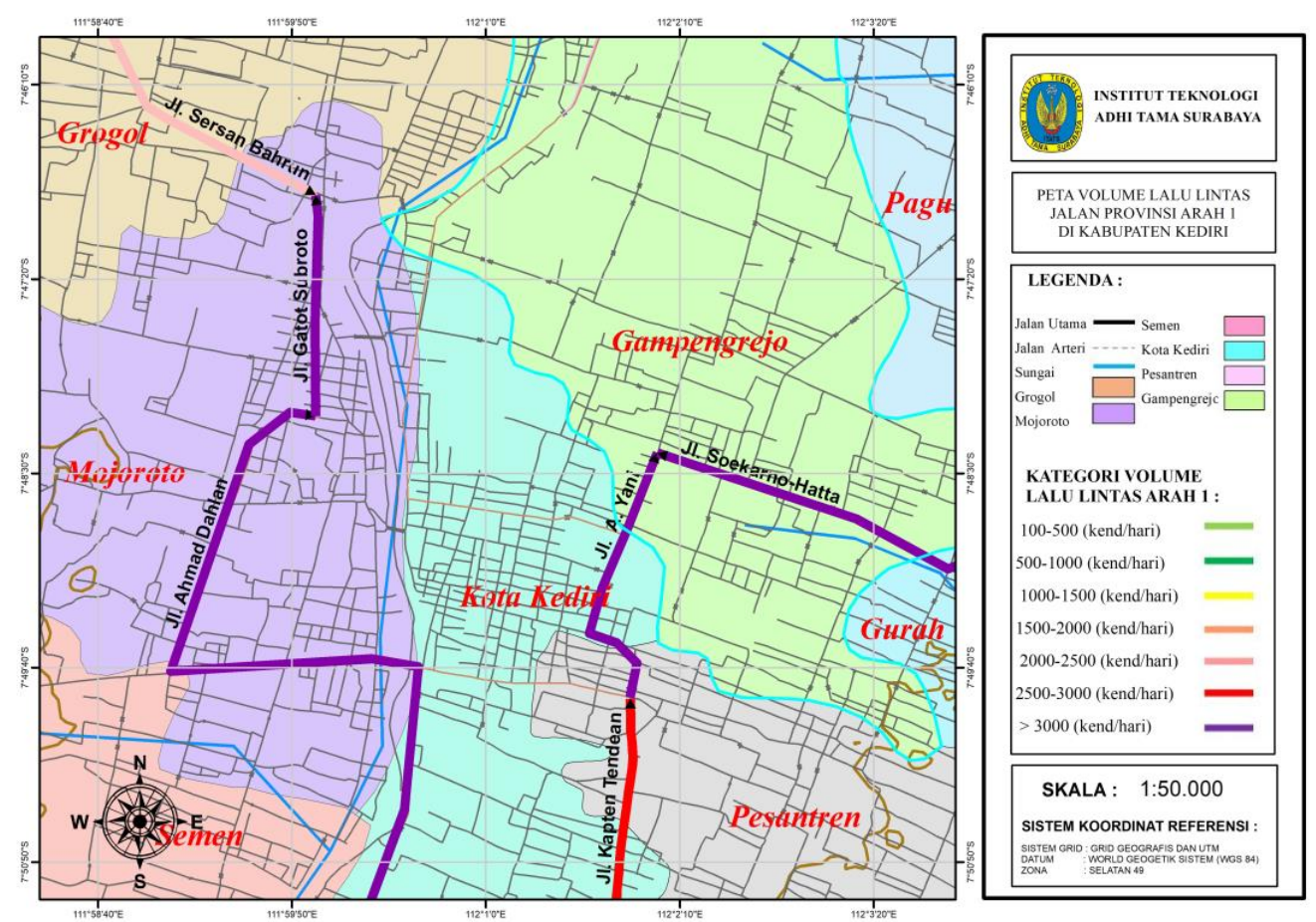

Gambar 4. Pemetaan volume lalu lintas jalan provinsi arah 1 di Kabupaten Kediri

Berdasarkan Gambar 3, dan Gambar 4, Hasil penelitian menunjukan bahwa sebagian besar ruas jalan provinsi di Kabupaten Kediri untuk arah ke 1 memiliki warna kuning dengan volume lalu lintas 1.000 - $1.500 \mathrm{smp} / \mathrm{jam}$. Pada ruas Jl. Soekarno-Hatta, Jl. Gatot Subroto, Jl. Ahmad Dahlan dan Jl. A. Yani berwarna ungu memiliki volume lalu lintas tertinggi dengan nilai $>3.000$ (SMP/jam), dan ruas Jl. Ki Hajar Dewantara, berwarna hijau muda memiliki volume lalu lintas terendah dengan nilai $100-500$ (SMP/jam).

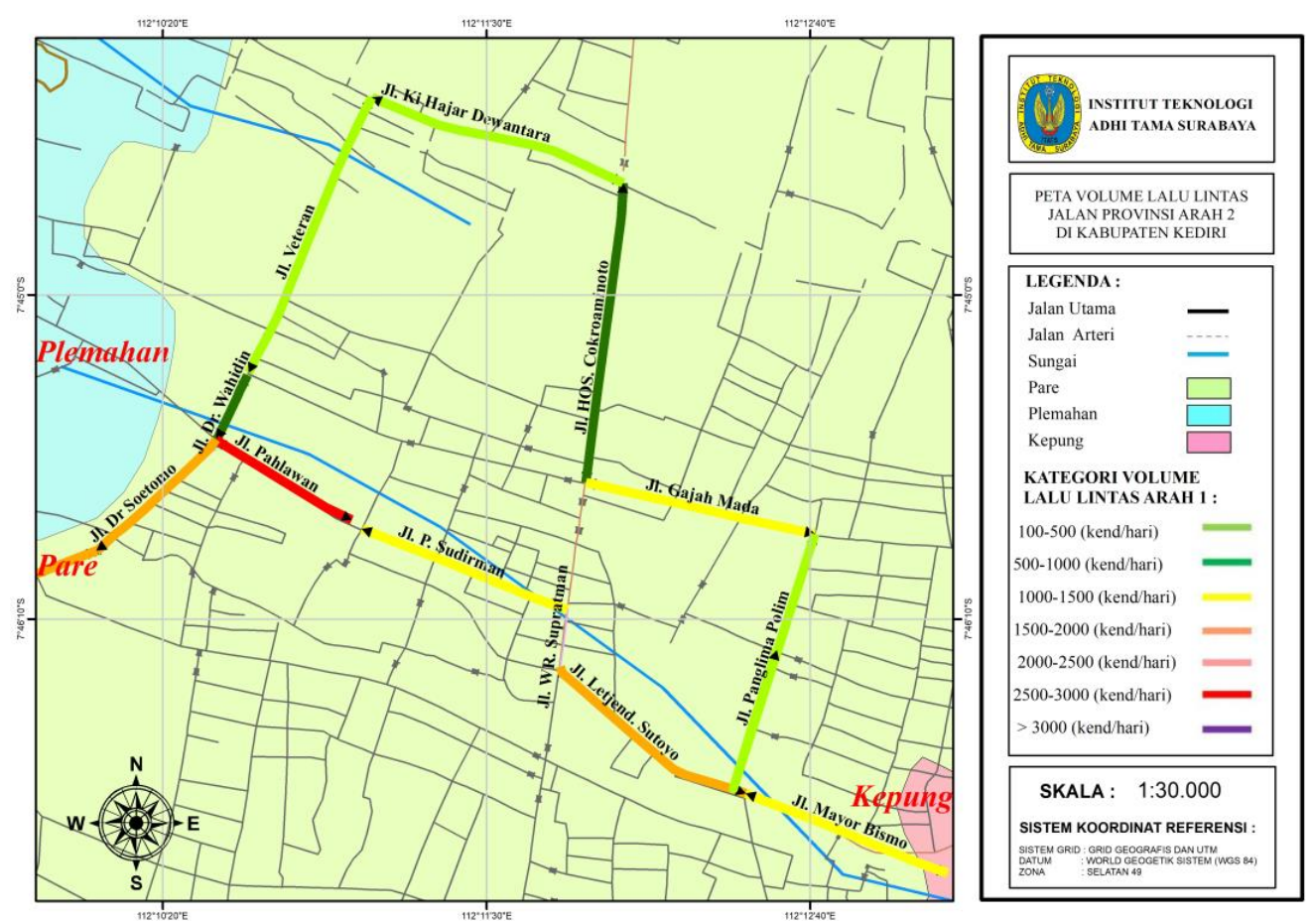

Gambar 5. Pemetaan volume lalu lintas jalan provinsi arah 2 di Kabupaten Kediri 


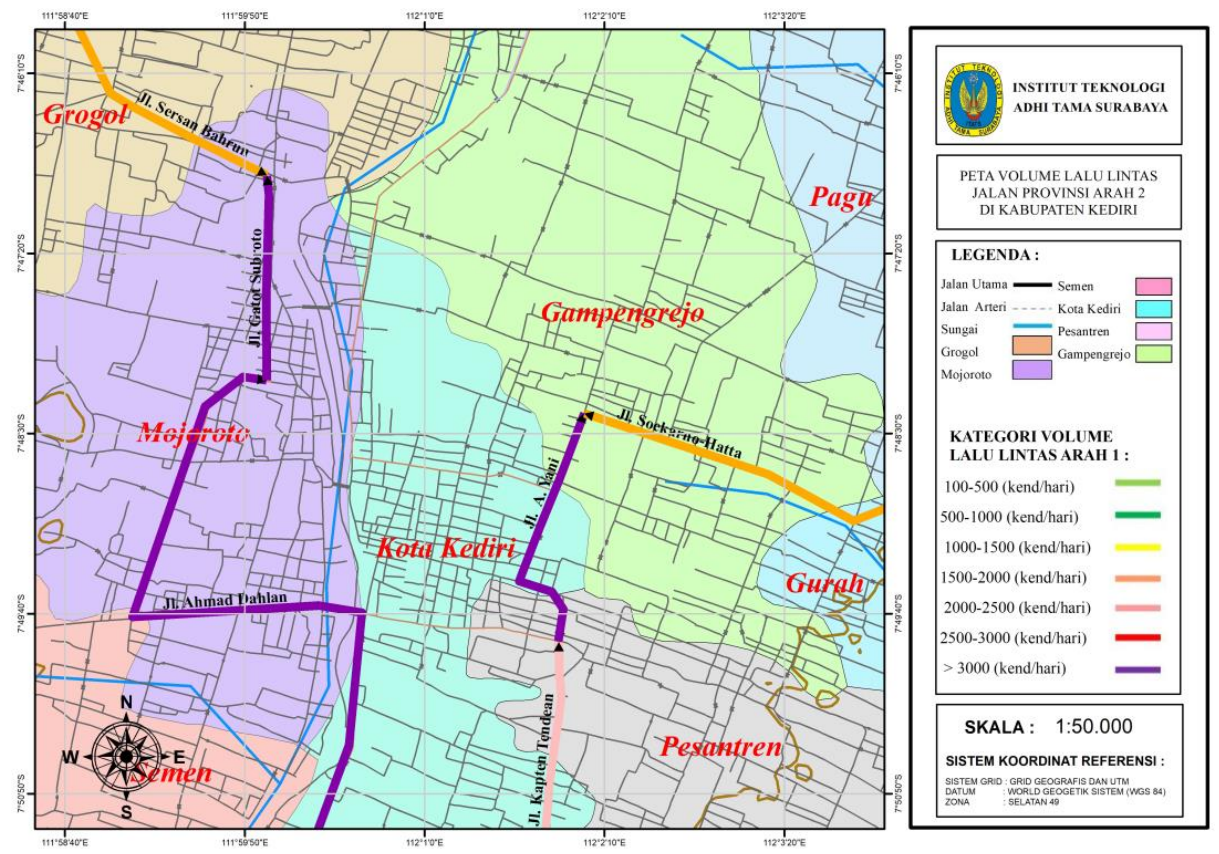

Gambar 6. Pemetaan volume lalu lintas jalan provinsi arah 2 di Kabupaten Kediri

Gambar 5 dan Gambar 6 hasil penelitian menunjukan bahwa sebagian besar ruas jalan provinsi di Kabupaten Kediri untuk arah ke 2 memiliki hijau muda dengan volume 100 - 500 smp/jam dan warna orange dengan volume 1.500 - $2.000 \mathrm{smp} / \mathrm{jam}$. Ruas Jl. Gatot Subroto, Jl. Ahmad Dahlan dan Jl. A. Yani berwarna ungu memiliki volume lalu lintas tertinggi dengan nilai $>3.000$.

\subsection{Pemetaan Berdasarkan Kapasitas Jalan Provinsi di Kabupaten Kediri}

Dengan berdasarkan pada MKJI tahun 1997, maka dapat ditentukan kapasitas jalan berdasarkan koefisien-koefisien berdasarkan hasil survei, selengkapnya dapat dilihat pada Tabel 2 Kapasitas Jalan Provinsi di kabupaten Kediri.

Tabel 2. Volume lalu lintas jalan provinsi di Kabupaten Kediri

\begin{tabular}{llccccccc}
\hline No & \multicolumn{1}{c}{ Nama Ruas } & $\begin{array}{c}\text { Panjang } \\
(\mathbf{k m})\end{array}$ & $\begin{array}{c}\text { Lebar } \\
\mathbf{( m )}\end{array}$ & $\mathbf{C o}$ & $\mathbf{F C w}$ & $\mathbf{F C s p}$ & FCsf & $\begin{array}{c}\text { C } \\
\text { (smp/jam) }\end{array}$ \\
& & & & & & & 2482 \\
1 & Jl. HOS. Cokroaminoto & 2.08 & 6.00 & 3100 & 0.91 & 1.00 & 0.88 & 1882 \\
2 & Jl. Ki Hajar Dewantoro & 1.76 & 5.00 & 3100 & 0.69 & 1.00 & 0.88 & 1882 \\
3 & Jl. Veteran & 2.01 & 5.00 & 3100 & 0.69 & 1.00 & 0.88 & 2728 \\
4 & Jl. Dr. Wahidin & 0.48 & 7.00 & 3100 & 1.00 & 1.00 & 0.88 & 2728 \\
5 & Jl. Gajah Mada & 1.78 & 7.00 & 3100 & 1.00 & 1.00 & 0.88 & 1882 \\
6 & Jl. Panglima Polim & 1.56 & 5.00 & 3100 & 0.69 & 1.00 & 0.88 & 2728 \\
7 & Jl. Mayor Bismo & 3.00 & 7.00 & 3100 & 1.00 & 1.00 & 0.88 & 2728 \\
8 & Jl. Letnan Sutoyo & 1.53 & 7.00 & 3100 & 1.00 & 1.00 & 0.88 & 2728 \\
9 & Jl. WR. Supratman & 0.41 & 7.00 & 1900 & 1.00 & 1.00 & 0.88 & 3137 \\
10 & Jl. Panglima Sudirman & 1.46 & 7.40 & 3100 & 1.02 & 1.00 & 0.88 & 2783 \\
11 & Jl. Pahlawan & 1.13 & 9.00 & 3100 & 1.15 & 1.00 & 0.88 & 2564 \\
12 & Jl. Dr. Soetomo & 1.53 & 6.50 & 3100 & 0.94 & 1.00 & 0.88 & 2567 \\
13 & Jl. Soekarno - Hatta & 1.36 & 6.00 & 3100 & 0.91 & 1.00 & 0.91 & 2482 \\
14 & Jl. Sersan Bahrun & 0.73 & 6.00 & 3100 & 0.91 & 1.00 & 0.88 & 2946 \\
15 & Jl. Gatot Subroto & 1.29 & 7.00 & 3100 & 1.00 & 1.00 & 0.91 & 2821 \\
16 & Jl. Ahmad Dahlan & 0.32 & 8.00 & 3100 & 1.08 & 1.00 & 0.88 & 2946 \\
17 & Jl. Kapten Tendean & 3.95 & 7.00 & 3100 & 1.00 & 1.00 & 0.88 & 2728 \\
18 & Jl. A. Yani & 0.64 & 12.00 & 1900 & 0.92 & 1.00 & 0.93 & 1626 \\
\hline
\end{tabular}


Selanjutnya dipetakan dengan warna berdasarkan hasil analisis perhitungan kapasitas jalan sesuai dengan asumsi penulis, untuk lebih jelasnya dapat dilihat pada Gambar 7 dan 8 Pemetaan kapasitas jalan provinsi di Kabupaten Kediri.

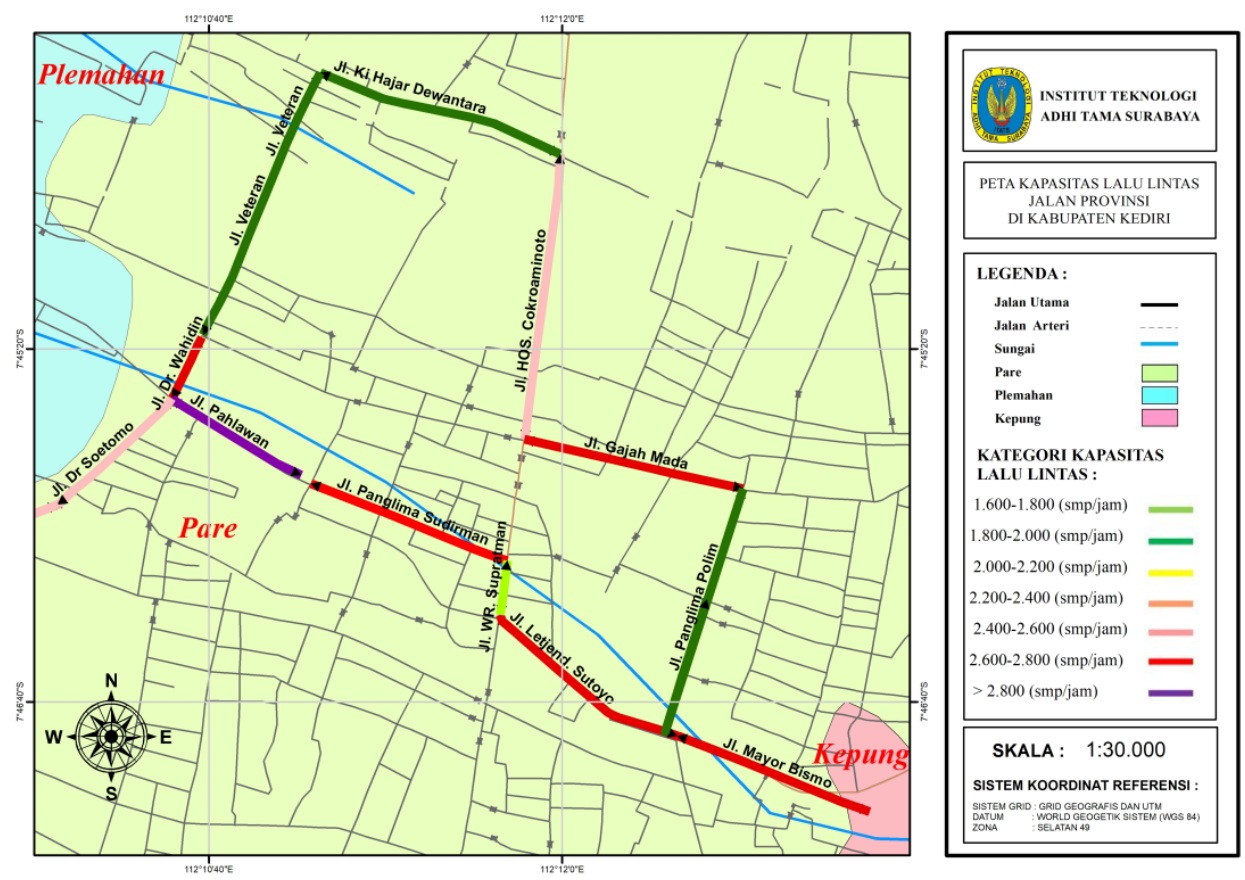

Gambar 7. Pemetaan volume lalu lintas jalan provinsi arah 2 di Kabupaten Kediri

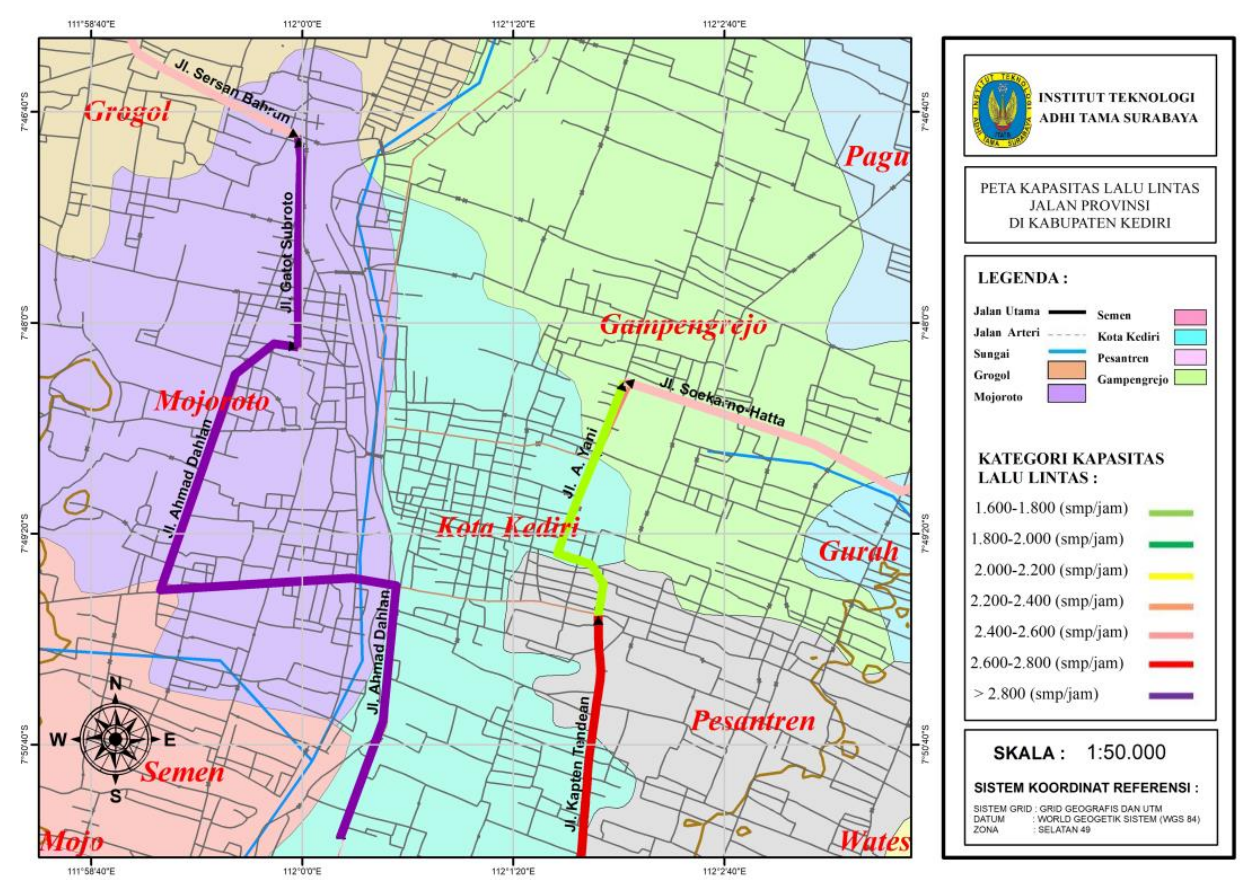

Gambar 8. Pemetaan volume lalu lintas jalan provinsi arah 2 di Kabupaten Kediri

Berdasarkan Gambar 7 dan Gambar 8, pada peta kapasitas jalan provinsi di Kabupaten Kediri (SMP/jam) terlihat bahwa, sebagian besar ruas jalan provinsi di Kabupaten Kediri memiliki warna merah dengan nilai lalu lintas harian rata - rata $2.600-2.800 \mathrm{smp} / \mathrm{jam}$. 


\subsection{Pemetaan Derajat Kejenuhan (DS) dan Tingkat Pelayanan Jalan (LoS)}

Setelah didapat kapasitas jalan dapat ditentukan Derajat kejenuhan atau Degree of Saturation (DS) berdasarkan MKJI 1997 dan indikator Level of Service (LoS), untuk lebih detail dapat dilihat di Tabel 3.

Tabel 3. Derajat kejenuhan dan tingkat pelayanan jalan

\begin{tabular}{|c|c|c|c|c|c|c|}
\hline \multirow{2}{*}{ No } & \multirow{2}{*}{ Nama Ruas } & \multirow{2}{*}{$\begin{array}{c}\mathrm{C} \\
\text { (smp/jam) }\end{array}$} & \multicolumn{2}{|c|}{ DS } & \multicolumn{2}{|c|}{ LOS } \\
\hline & & & arah 1 & $\operatorname{arah} 2$ & arah 1 & arah 2 \\
\hline \multicolumn{7}{|c|}{ Wilayah Kabupaten Kediri } \\
\hline 1 & Jl. HOS. Cokroaminoto & 2482 & 0.24 & 0.20 & B & A \\
\hline 2 & J1. Ki Hajar Dewantoro & 1882 & 0.15 & 0.11 & A & A \\
\hline 3 & Jl. Veteran & 1882 & 0.14 & 0.13 & A & A \\
\hline 4 & Jl. Dr. Wahidin & 2728 & 0.15 & 0.16 & A & A \\
\hline 5 & Jl. Gajah Mada & 2728 & 0.19 & 0.17 & A & A \\
\hline 6 & Jl. Panglima Polim & 1882 & 0.24 & 0.11 & B & A \\
\hline 7 & Jl. Mayor Bismo & 2728 & 0.24 & 0.21 & B & B \\
\hline 8 & J1. Letnan Sutoyo & 2728 & 0.25 & 0.31 & B & B \\
\hline 9 & Jl. WR. Supratman & 1672 & 0.66 & 0.00 & $\mathrm{C}$ & - \\
\hline 10 & J1. Panglima Sudirman & 2783 & 0.26 & 0.28 & B & B \\
\hline 11 & J1. Pahlawan & 3137 & 0.34 & 0.41 & B & B \\
\hline 12 & Jl. Dr. Soetomo & 2564 & 0.32 & 0.32 & B & $\mathrm{B}$ \\
\hline 13 & Jl. Soekarno - Hatta & 2567 & 0.54 & 0.37 & $\mathrm{C}$ & $\mathrm{B}$ \\
\hline \multicolumn{7}{|c|}{ Wilayah Kediri } \\
\hline 14 & Jl. Sersan Bahrun & 2482 & 0.48 & 0.34 & $\mathrm{C}$ & $\mathrm{B}$ \\
\hline 15 & Jl. Gatot Subroto & 2821 & 0.64 & 0.82 & $\mathrm{C}$ & $\mathrm{D}$ \\
\hline 16 & Jl. Ahmad Dahlan & 2946 & 0.65 & 0.79 & $\mathrm{C}$ & $\mathrm{D}$ \\
\hline 17 & Jl. Kapten Tendean & 2728 & 0.51 & 0.45 & $\mathrm{C}$ & $\mathrm{C}$ \\
\hline 18 & Jl. A.Yani & 1626 & 1.12 & 0.96 & $\mathrm{~F}$ & $\mathrm{E}$ \\
\hline
\end{tabular}

Selanjutnya dipetakan berdasarkan warna hasil analisis perhitungan derajat kejenuhan dengan ukuran kualitatif indeks tingkat pelayanan jalan atau Los of Service (LoS) sesuai dengan asumsi penulis, untuk lebih jelasnya dapat dilihat pada Gambar 9, 10, 11 dan 12 Pemetaan derajat kejenuhan dan tingkat pelayanan jalan provinsi di Kabupaten Kediri.

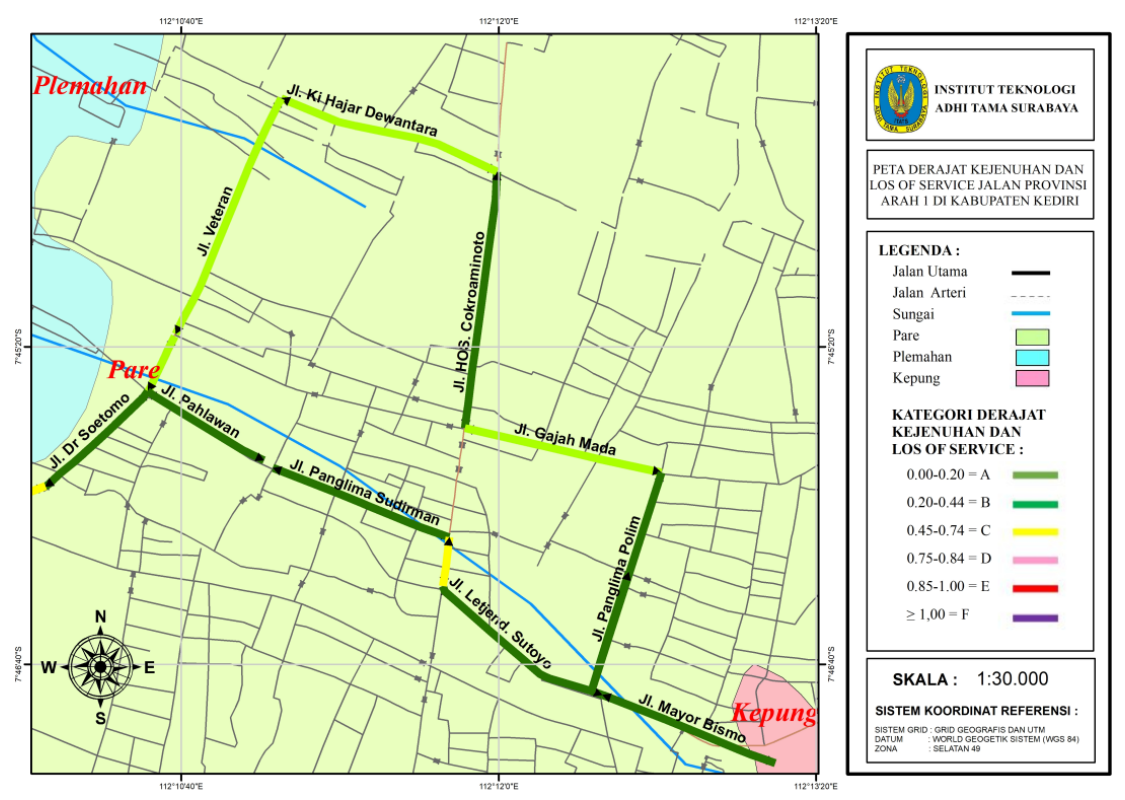

Gambar 9. Pemetaan derajat kejenuhan dan tingkat pelayanan jalan arah 1 pada Jalan Provinsi di Kabupaten Kediri 

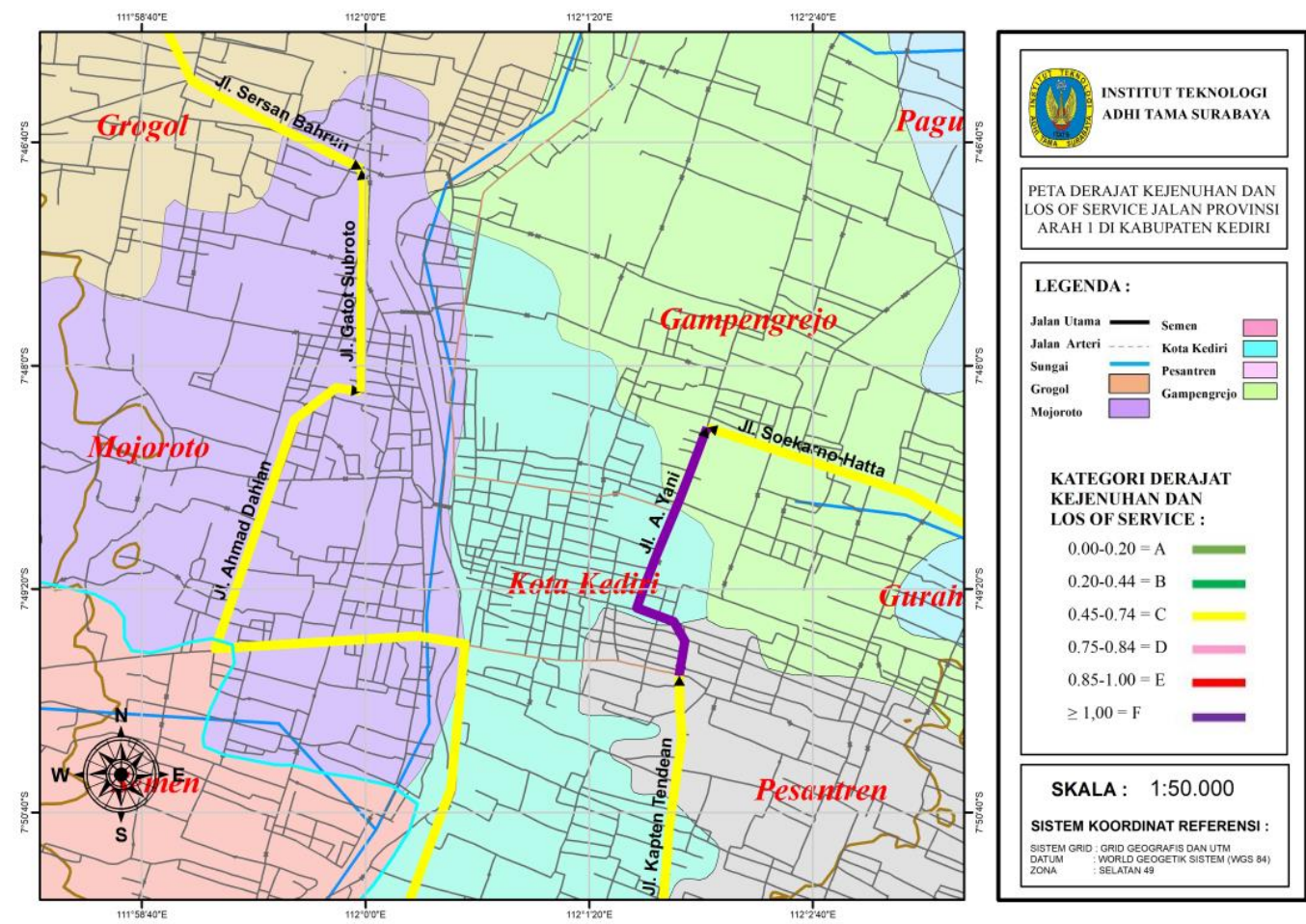

Gambar 10. Pemetaan derajat kejenuhan dan tingkat pelayanan jalan arah 1 pada Jalan Provinsi di Kabupaten Kediri
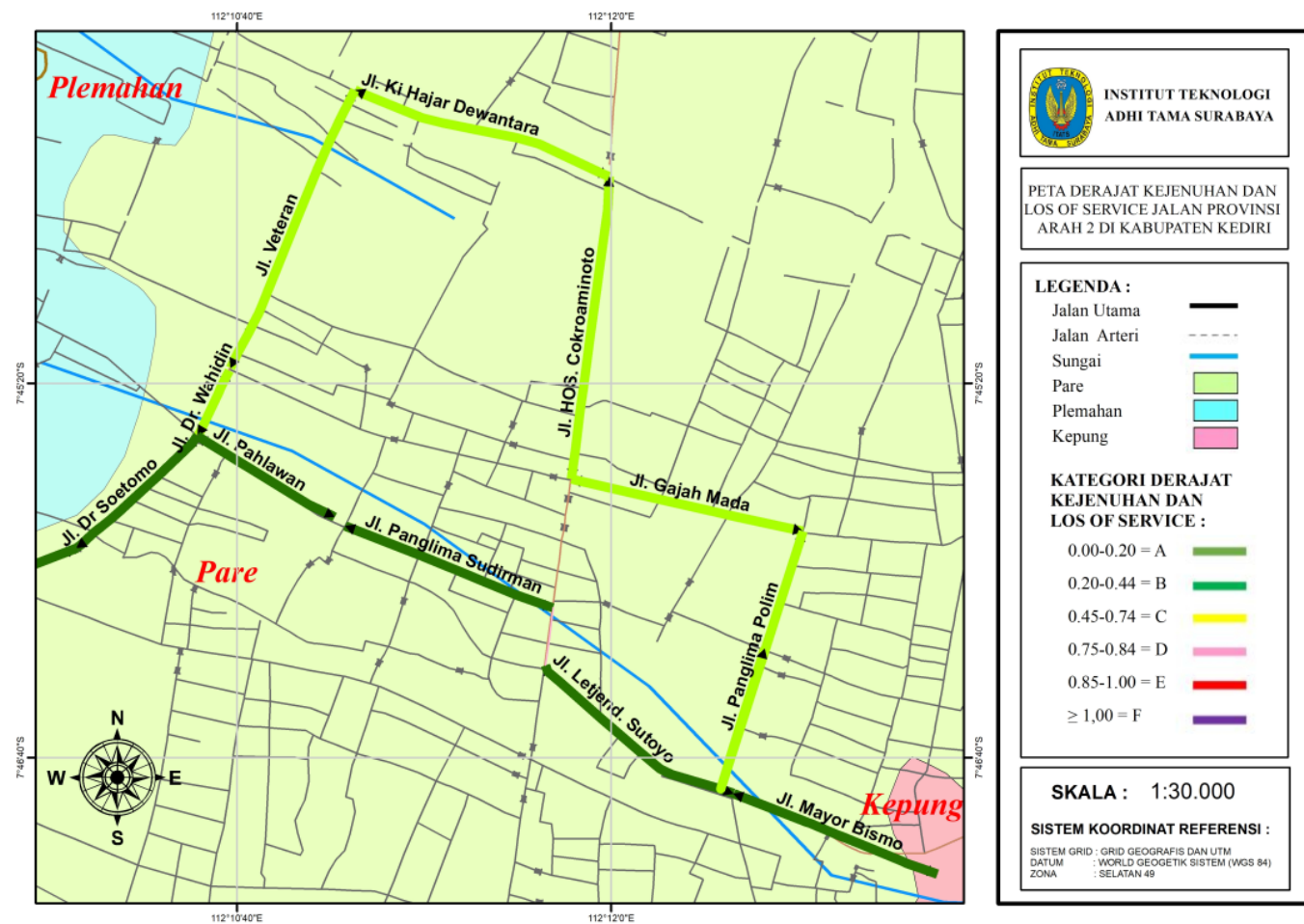

Gambar 11. Pemetaan derajat kejenuhan dan tingkat pelayanan jalan arah 2 pada Jalan Provinsi di Kabupaten Kediri. 


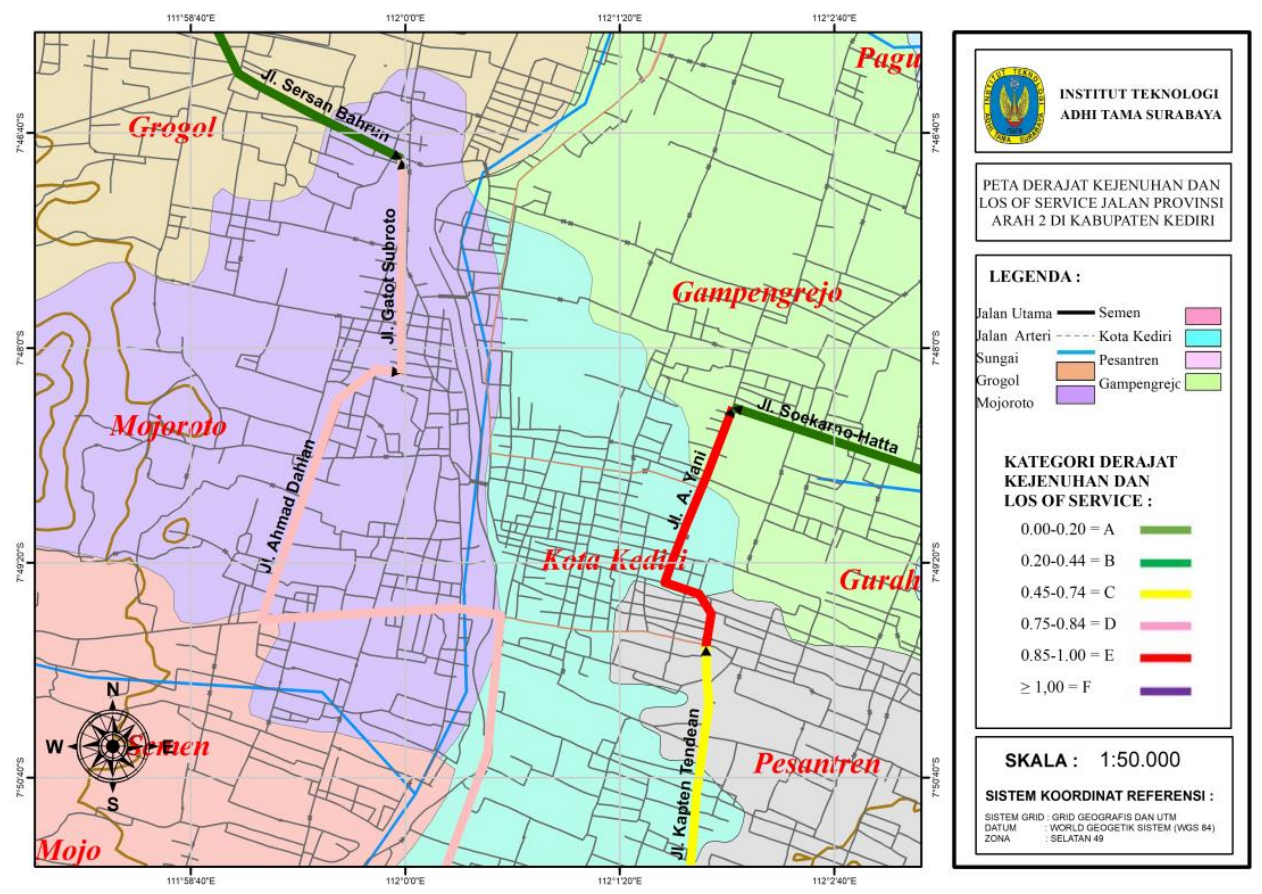

\section{Gambar 12. Pemetaan derajat kejenuhan dan tingkat pelayanan jalan arah 2 pada Jalan Provinsi di Kabupaten Kediri.}

Berdasarkan Gambar 11, 12 seperti garis ruas jalan berwarna hijau muda memiliki nilai 0,00 0,20 dengan kategori $\mathrm{A}$, warna hijau dengan nilai 0,20 - 0,44 dengan kategori $\mathrm{B}$, warna kuning dengan nilai 0,45 - 0,74 dengan kategori $\mathrm{C}$, warna merah muda dengan nilai 0,75-0,84 dengan kategori $\mathrm{D}$, warna merah dengan nilai $0,85-1,00$ dengan kategori $\mathrm{E}$, dan warna ungu dengan nilai $\geq 1,00$ dengan kategori F. Ruas Jl. Veteran, Jl. Wahidin dan Jl. Ki Hajar Dewantara, berwarna hijau muda memiliki derajat kejenuhan (DS) terendah dengan nilai 0.00-0.20 dengan kategori A. Sedangkan ruas Jl. A.Yani berwarna ungu memiliki derajat kejenuhan (DS) tertinggi dengan nilai DS $>1.00$ dengan kategori $\mathrm{F}$ pada tingkat pelayanan jalan yang berarti zona ini memerlukan penanganan meliputi rekayasa lalu lintas atau peningkatan jalan diharapkan akan meningkatkan kapasitas jalan tersebut.

\section{Kesimpulan}

\subsection{Kesimpulan}

Berdasarkan analisa data perhitungan kinerja ruas jalan provinsi Kabupaten Kediri, maka : (1) Berdasarkan metode MKJI 1997 derajat kejenuhan dan tingkat pelayanan jalan pada jalan provinsi di Kabupatrn Kediri sebagian besar memiliki nilai 0,20 - 0,44 dengan tingkat pelayanan B. Dan pada ruas jalan A.Yani memiliki rasio derajat kejenuhan sebesar 0.85- 1.00 dengan tingkat pelayanan E dan rasio derajat kejenuhan sebesar $>1.00$ dengan tingkat pelayanan F. (2) Tingkat pelayanan jalan (LoS) pada ruas jalan provinsi di Kabupaten Kediri sebagian besar masih berwarna hijau muda, hijau, dan kuning dengan kategori A, kategori B dan kategori C. Namun tidak pada ruas jalan A. Yani yang berwarna ungu, memiliki tingkat pelayanan jalan (LoS) dengan kategori F. Pemetaan tersebut dapat dilihat dalam Gambar 9, Gambar 10, Gambar 11, dan Gambar 12.

\subsection{Saran}

Berdasarkan hasil dari penelitian, penulis dapat memberikan saran sebagai berikut: (1) Perlu adanya riset yang sangat detail terkait ruas jalan yang memiliki nilai LoS E sehingga dapat terdeteksi penyebab kemacetan dan aka nada alternatif solusi untuk mengatasi permasalahan tersebut. (2) Pihak Dinas PU Jatim dapat segera mengantisipasi terjadi kemacetan yang ada beberapa ruas jalan di 
kabupaten Kediri agar tingkat kemacetan tidak meningkat. (3) Penelitian ini bisa dikembangkan lebih lanjut dengan jalan - jalan alternatif untuk pengalihan dari kawasan jalan macet dengan menggunakan rambu pembantu.

\section{Referensi}

[1] Abubakar, dkk.1995. Sistim Transportasi Kota. Jakarta: Direktur Jenderal Perhubungan Darat.

[2] Abubakar, dkk.1996. Menuju Lalu Lintas dan Angkutan Jalan Yang Tertib, edisi yang disempurnaka. Jakarta: Direktur Jenderal Perhubungan Darat.

[3] Budi Prasetyo, Agustinus.2009. Pemetaan Lokasi Rawan dan Resiko Bencana Banjir di Kota Surakarta Tahun 2007. Skripsi tidak diterbitkan. Surakarta: Fakultas Keguruan dan Ilmu Pendidikan Universitas Sebelas Maret Surakarta.

[4] Aronoff, Stan.1989. Geographic Information System; A Management Perspective. Ottawa: WDL, Publications.

[5] Brinker, Russell, C., dan Paul, R. Wolf. 1984. Elementary Surveying, atau Dasar-Dasar Pengukuran Tanah, Terj. Djoko Walijatun, Jakarta: Erlangga.

[6] DAI. 2007. Panduan Pemetaan Partisipatif, Malang: Environmental Services Program.

[7] Gistut. 1994. Sistem Informasi Geografis. Gramedia Pustaka Utama.

[8] Hobbs, F.D. 1979. Traffic Planning and Engineering, Second edition, edisi Indonesia, 1995, terjemahan Suprapto T.M. dan Waldijono, Perencanaan dan Teknik Lalu Lintas, Yogyakarta: Edisi kedua, Gadjah Mada University Press Yogyakarta.

[9] Kaisar, Abd. 2016. Analisis Kinerja Lalu Lintas Jalan pada Jaringan Jalan Arteri di Kota Makassar Berbasis SIG Berdasarkan Metode MKJI 1971. Skripsi tidak diterbitkan. Makassar : Universitas Hasanuddin.

[10] _ 1997. Manual Kapasitas Jalan Indonesia (MKJI). Departemen Pekerjaan Umum Direktorat Jenderal Bina Marga. 